\title{
EDWARD SAPIR: FORMA CULTURAL E EXPERIÊNCIA INDIVIDUAL
}

Segundo o nível de análise, temos de operar com culturas de grupos e culturas de indivíduos. ${ }^{1}$

Edward Sapir

I Desde sua publicação, na segunda década do século XX, "Culture: genuine and spurious" tem sido referência significativa nos debates sobre as concepções antropológicas de cultura.

O autor o redigiu ainda no ano de 1918, ao fim da Primeira Guerra Mundial. Publicado originalmente sob o título "Civilization and culture", em duas pequenas, mas importantes, revistas literárias norte-americanas - Dial (1919) e Dalhousie Review (1922) -, é só em 1924 que o texto vai ser publicado no American Journal of Sociology, em sua forma completa, tal como o conhecemos hoje (Stocking Jr., 1989: 216).

Dez anos após a morte do autor, é incluído numa seleção de textos organizada por David G. Mandelbaum, Edward Sapir: selected writings in language, culture, and personality (Sapir, [1949] 1985). Nos anos sessenta, alguns de seus artigos sobre cultura e personalidade (incluindo-se "Culture: genuine and spurious") foram reunidos num livro organizado e publicado na França pelo sociólogo Christian Baudelot (1967). Seu clássico livro de introdução ao estudo da linguagem, Language (1921), foi o único publicado em vida. Além das coletâneas de Mandelbaum e Baudelot, um outro livro póstumo foi editado em 1994 por Judith Irvine a partir de notas de aula de um curso sobre "psicologia da cultura", conduzido por Sapir na Universidade de Yale alguns anos antes de sua morte: The psychology of culture: a course of lectures (Sapir, 1994). A maior parte de sua obra foi publicada na forma de numerosos artigos dispersos em revistas profissionais. Nas últimas décadas do século XX, especialmente a partir dos 
anos oitenta, quando das comemorações do seu centenário de nascimento, suas obras completas foram editadas nos Estados Unidos.

O pensamento de Sapir, expresso em seus textos sobre cultura, vem sendo objeto de interesse renovado por parte da comunidade dos antropólogos. De certo modo, esses textos trazem de forma sofisticada alguns dos problemas e críticas dirigidos ao conceito de cultura nos debates desencadeados pelas chamadas antropologias "pós-modernas" e "pós-estruturalistas" dos anos oitenta e noventa. No entanto, pela sua relevância teórica, eles parecem transcender esse contexto histórico-intelectual, assim como transcenderam a época em que foram escritos: os anos vinte e trinta do século XX. Nesse conjunto de textos, "Culture: genuine and spurious" destaca-se pela atualidade e alcance de suas formulações.

II Uma permanente tensão entre "disciplina profissional" e "ideologia cultural" perpassa a moderna tradição antropológica (Stocking Jr., 1989: 248). Nossas carreiras e nosso trabalho intelectual, enquanto antropólogos, oscilam entre esses polos. O texto de Sapir exibe essa tensão de modo notável. Regna Darnell o situa “... entre estética e antropologia ..." 2 (1990: 169). Integrando o discurso modernista de crítica cultural da época, tendo um papel fundador na "sensibilidade etnográfica dos anos 20", o artigo é também considerado um documento fundamental no "desenvolvimento do conceito antropológico de cultura" (Stocking Jr., 1989: 216).

Quanto ao primeiro aspecto, a distinção entre "civilização" e "cultura" é decisiva, sendo um dos pontos fundamentais explorados ao longo do artigo. Naquele contexto histórico e intelectual, a noção de "cultura" (em oposição a "civilização") está associada às formas de vida "autênticas" em contraste com as formas "espúrias" supostamente características das grandes metrópoles modernas.

É possível surpreender aí a busca modernista obsessiva pela autenticidade. No entanto, essa noção parece funcionar de modos distintos na reflexão de Sapir. Se, por um lado, ela expressa um valor central das ideologias culturais do modernismo, por outro ela é trazida no texto como um critério por meio do qual se pode iluminar analiticamente algumas dimensões fundamentais da vida sociocultural: por exemplo, a sua dimensão da experiência individual.

Vale enfatizar que a noção de autenticidade não é apenas um valor ideológico alocado no indivíduo entendido como uma entidade naturalmente dada. Segundo Sapir, “... um cosmo pessoal - um mundo pessoal de significados - é uma cultura distinta..."3 (Sapir, 1994: 198). Em outras palavras, cada personalidade é, no limite, uma cultura, e, enquanto tal, o efeito, ao mesmo tempo que a condição, de um padrão mais ou menos coerente de símbolos. Ou seja, não há indivíduo (ou "personalidade") e não há criatividade individual sem processos inconscientes de padronização cultural. 
III É a condição de linguista que singulariza a voz de Sapir na conversação sobre a noção antropológica de "cultura" e suas relações com a "personalidade". Sua reflexão incide primeiramente sobre a linguagem; em seguida, sobre a cultura e suas relações com a personalidade. As relações entre linguagem e cultura são, para ele, de uma similaridade notável. Do seu ponto de vista, as culturas, assim como a linguagem, formam sistemas complexos cujos termos se condicionam reciprocamente. Segundo alguns autores, em um texto de 1925 (Sapir, [1949] 1985: 33-45), Sapir foi o primeiro a formular a relevância fundamental da linguística para as ciências humanas (Hymes, 1985: 598).

Esse pressuposto permite a Sapir distanciar-se criticamente de uma série de concepções. Primeiramente, das concepções evolucionistas. Para ele, a cultura não resulta de um processo evolutivo determinado por uma origem e atravessando estágios teleologicamente. Nem é a cultura "causada" por uma outra dimensão supostamente "mais básica", seja a sociedade, seja a ecologia, seja a biologia ou a psicologia. Sapir assume uma posição claramente antideterminista. Tampouco a cultura é, para ele, um agregado de traços culturais a se difundir historicamente pelo planeta. Ele distancia-se também daquelas concepções que entendem a cultura como padrões comportamentais. Finalmente, um distanciamento crítico fundamental para entendermos a concepção de cultura em Sapir é o que ele empreende em relação às teorias funcionalistas, nas quais as culturas devem, para existir, preencher alguma função utilitária. Como linguista, assim como antropólogo, Sapir vai enfatizar as formas. Contra os funcionalistas, que enfatizavam a dimensão consciente e utilitária das práticas socioculturais, a cultura para Sapir, a exemplo da linguagem, é um processo simbólico inconsciente de padronização.

Esse processo, por sua vez, seja na linguagem, seja na cultura, não é a simples expressão de padrões fixos e homogêneos. E nem estes se impõem externamente sobre os indivíduos. Para Sapir, "A cultura então não é algo dado, mas algo a ser gradual e duramente descoberto." ${ }^{4}$ (1985: 596). Em outras palavras, a cultura não é algo simplesmente transmitido de modo pronto e acabado: é uma aquisição. Desse modo, para Sapir, os padrões culturais “... não podem ser, de modo realista, desconectados daquelas organizações de ideias e sentimentos que constituem o indivíduo..." ${ }^{5}$ (1985: 512). Ou seja, os indivíduos não apenas "executam" os padrões culturais; na verdade, podem ter um papel criativo fundamental, uma vez que esses padrões estão sujeitos a uma “... interminável reavaliação na medida em que nos deslocamos de indivíduo para indivíduo e de um período a outro..." ${ }^{6}$ (1994: 199), sendo simultaneamente condição e objeto de um processo permanente de reconstrução. E aqui a noção de "autenticidade" aponta para a possibilidade e a necessidade dessa dimensão criativa da cultura.

Assinale-se que o primado da "experiência individual" (Handler, 2005: 94) não significa que Sapir associe um valor absoluto positivo (ou negativo) ao 
indivíduo. Há, em sua concepção de cultura, uma tensão entre "criatividade individual" e "imperativo cultural" (Handler, 1986:148). Portanto, sua concepção de cultura passa pela ideia de um processo permanente de reconstrução, seja por parte do observador, seja por parte do observado. Assinale-se que, ao pensar o indivíduo, as psicologias às quais Sapir recorre é a da Gestalt e a psicanálise, voltadas para a dimensão das formas e do inconsciente. Segundo Sapir, existe uma percepção intuitiva das formas linguísticas e culturais: "A projeção sobre o comportamento social de um inato sentido de forma é um processo intuitivo e é meramente uma fase especial daquele funcionamento mental que encontra sua expressão mais nítida na matemática e sua mais pura realização estética na composição musical" 7 (1985: 344). Esse "inato sentido de forma"8 é a condição sine qua non para a criatividade individual, seja nas formas de vida social, seja nas elaborações artísticas, ambas partilhando a dimensão estética.

Se, por um lado, a obra antropológica de Sapir pode ser percebida como expressão de uma "sensibilidade romântica" que atravessa a história da antropologia (Stocking Jr., 1989: 7), por outro pode-se perceber em sua reflexão sobre a cultura uma tendência clássica ou uma espécie de "romantismo anti-romântico", segundo a expressão de Richard Handler (2005: 73). Valorizando a forma, o "imperativo cultural", ao mesmo tempo que a "criatividade individual", o que está em foco em seu pensamento é a tensão entre um e outro polo. No entanto, para que se realize dinamicamente essa relação, as formas culturais, assim como as formas linguísticas, não podem ser entendidas como todos absolutamente coerentes: "Se a linguagem fosse absolutamente 'gramatical', ela seria uma máquina perfeita de expressão conceitual. Infelizmente, ou felizmente, nenhuma linguagem é tiranicamente consistente. Todas as gramáticas vazam" ${ }^{9}$ (Sapir, [1921] 1949: 38). Essas "inconsistências" são, para Sapir, a condição e o efeito da ação criativa que os indivíduos podem realizar sobre a linguagem e sobre cultura, seja do ponto de vista de seres humanos comuns em sua vida cotidiana, seja do ponto de vista dos analistas da cultura, seja do ponto de vista dos artistas criadores.

É, no mínimo, terapêutico lembrar que afinal, assim como as gramáticas, as culturas nos expõem a esse permanente horizonte de possibilidades a ser criativamente explorado. Apesar do tom pessimista que "Culture: genuine and spurious" eventualmente assume, o tema ressoa de forma generosa em suas páginas. Não é pouco para aqueles que, como nós, vivemos culturalmente em tempos mais que sombrios. 
IV No Brasil, é sobretudo nos círculos profissionais da linguística que a obra de Sapir vai encontrar repercussão, especialmente através de Joaquim Mattoso Câmara Júnior (1904-1970), seu tradutor e editor. Não se pode dizer o mesmo em relação às ciências sociais.

Language: an introduction to the study of speech foi traduzido no Brasil por Mattoso Câmara em 1938, mas publicado somente em 1954 (Mattoso Câmara, 1980). A segunda edição é de 1969 e uma re-edição foi lançada em 1980 pela Ed. Perspectiva (Sapir, 1980). Atualmente, encontra-se esgotado. Há também uma excelente coletânea de textos sobre linguística organizada por Joaquim Mattoso Câmara (Linguística como ciência) e publicada pela Livraria Acadêmica (Sapir, 1969).

Nas ciências sociais, não há no Brasil nenhuma publicação do conjunto dos textos de Sapir sobre cultura. É possível assinalar a tradução de "Culture: genuine and spurious" numa coletânea organizada por Donald Pierson (19001995) e publicada em 1949. Há também um outro texto ("Comunicação e contacto social”) incluído numa coletânea organizada pelos sociólogos Fernando Henrique Cardoso e Octavio Ianni, em 1971.

Do ponto de vista editorial, a publicação de "Cultura: autêntica e espúria” vem preencher de maneira mínima um vazio considerável no Brasil em relação à obra antropológica desse autor.

Recebido para publicação em agosto de 2012. 
EDWARD SAPIR: FORMA CULTURAL E EXPERIÊNCIA INDIVIDUAL

30

José Reginaldo Santos Gonçalves é professor do Programa de Pós-Graduação em Sociologia e Antropologia (PPGSA) e do Departamento de Antropologia Cultural da Universidade Federal do Rio de Janeiro (UFRJ), onde também é Pesquisador Associado do Programa Avançado de Cultura Contemporânea (PACC), além de dirigir o Laboratório de Antropologia da Arquitetura e Espaços e o Núcleo de Antropologia dos Objetos. Foi Visiting Scholar na Universidade de Yale na condição de Professor Senior CAPES/Fulbright (no MacMillan Center for International and Area Studies). 


\section{NOTAS}

1 "According to our scale of treatment, we have to deal with the cultures of groups and the cultures of individuals".

2 "[...] between aesthetics and anthropology [...]".

3 "[...] a personal cosmos - a personal world of meanings - is a separate culture [...]"

4 "Culture is then not something given but something to be gradually and gropinly discovered".

5 “[...] cannot be realistically disconnected from those organizations of ideas and feelings which constitute the individual [...]"

6 "[...] endless revaluation as we pass from individual to individual and from one period to another".

7 "The projection in social behavior of an innate sense of form is an intuitive process and is merely a special phase of that mental functioning that finds its clearest voice in mathematics and its most nearly pure aesthetic embodiment in plastic and musical design".

8 "innate sense of form".

9 'Were a language ever completely 'grammatical', it would be a perfect engine of conceptual expression. Unfortunately, or luckily, no language is tyrannically consistent. All grammars leak".

\section{REFERÊNCIAS BIBLIOGRÁFICAS}

Darnell, Regna. Edward Sapir: linguist, anthropologist, humanist. Berkeley: The University of California Press, 1990.

Handler, Richard. Vigorous male and aspiring female: poetry, personality, and culture in Edward Sapir and Ruth Benedict. In: Stocking Jr., George W. (org.). Malinowski, Rivers, Benedict and Others: essays on culture and personality. Madison: The University of Wisconsin Press, 1986, p. 127-155.

. Critics against culture: anthropological observers of mass society. Madison: The University of Wisconsin Press, 2005. Hymes, Dell H. Epilogue. In: Sapir, Edward, Selected writings in language, culture, and personality. (Org. David G. Mandelbaum). Berkeley: The University of California Press, [1949] 1985, p. 598-600. 
Kroeber, Alfred L. The nature of culture. Chicago: The University of Chicago Press, 1952.

Mattoso Câmara, Joaquim. Advertência à $2^{\mathrm{a}}$ edição. In: Sapir, Edward. A Linguagem. São Paulo: Perspectiva, [1921] 1980.

Sapir, Edward. Language: an introduction to the study of speech. San Diego: HJB Books, [1921] 1949.

A Linguagem. São Paulo: Perspectiva, [1921] 1980. Cultura: genuína e espúria. In: Pierson, Donald (org.). Estudos de organização social. São Paulo: Martins Editora, 1949.

Anthropologie. (Org. Christian Baudelot). Paris: Éditions de Minuit. 1967.

Comunicação e contacto social. In: Cardoso, Fernando Henrique \& Ianni, Octavio. Homem e sociedade: leituras básicas de sociologia geral. São Paulo: Cia. Editora Nacional, 1971, p. 161-167.

. Linguística como ciência. (Textos organizados por J. Mattoso Câmara). Rio de Janeiro: Livraria Acadêmica, 1969.

Selected writings in language, culture, and personality. (Org. David G. Mandelbaum). Berkeley: The University of California Press, [1949] 1985.

The psychology of culture: a course of lectures (Org. Judith Irvine). Berlim/Nova York: Mouton de Gruyer, 1994.

Stocking Jr., George W. The ethnographic sensibility of the 1920s: essays on anthropological sensibilities. In: ___-_ (org.). Romantic motives: essays on anthropological sensibility. Madison: The University of Wisconsin Press, 1989, p. 208-276. 
Palavras-chave: Resumo:

Cultura; Linguagem; O artigo discute a perspectiva de Edward Sapir sobre a Forma; Autenticidade; noção de cultura. O autor assinala que o fato de Sapir ser Experiência individual. um linguista desempenha um papel crucial para o entendimento da singularidade dessa perspectiva. $\mathrm{O}$ artigo assinala ainda a importância que assume nessa perspectiva a noção de "forma" como uma dimensão fundamental na linguagem e na vida social. Isto permite a Sapir formular uma critica radical às concepções evolucionistas, difusionistas e funcionalistas da cultura. O autor mostra ainda que a noção de "autenticidade" parece desempenhar uma função significativa na concepção de cultura em Sapir, na medida em que, para esse autor, a cultura (as culturas autênticas) existe necessariamente por meio de experiências individuais singulares.

Keywords: Abstract:

Culture; Language; Form;

The author discusses in this article Edward Sapir's perAuthenticity; Individual spective on culture. He stresses that the fact that Sapir is experience. primarily a linguist plays a central role in order to understand the singularity of such a perspective. The author also stresses the importance of the notion of "form" in language as well as in social life. This emphasis on form makes possible a radical criticism of evolutionist, diffusionist, and functionalist concepts of culture. According to the author, the notion of authenticity plays an important role in Sapir's concept of culture once for that author culture (authentic cultures) necessarily exists by means of singular individual experiences. 